\title{
Evolution de la composition chimique et de la flore microbienne du fromage de Vacherin au cours de la maturation
}

\author{
par
}

T. SOZZI et D. SHEPHERD

Société d'Assistance Technique pour Produits Nestlé s.a. Laboratoire Industriel Orbe, 1350 Orbe (Suisse)

(avec la collaboration technique de Mlle M. R. CLELAND)

\section{Introduction}

La production du fromage de "Vacherin du Mont-d'Or » est très limitée dans le temps et dans l'espace. Il est produit entre septembre et mars dans une région spécifique du Jura Suisse. Ce Vacherin diffère du Vacherin à fondue ou Vacherin fribourgeois qui est fabriqué pendant toute l'année dans les autres régions de la Suisse.

La caractéristique principale du Vacherin du Mont-d'Or réside en une maturation très courte d'environ $20 \mathrm{j}$. Il a un goût peu prononcé, mais typique ; il n'est jamais amer et sa structure est très crémeuse. Le Vacherin est préparé à partir de lait entier et il a un extrait sec d'environ 45 p. 100.

La maturation se fait dans des caves ayant une humidité relative de $98 \mathrm{p} .100$ et une température de $13^{\circ} \mathrm{C}$ à $15^{\circ} \mathrm{C}$. La production annuelle de Vacherin est à peu près de $500000 \mathrm{~kg}$.

Les micro-organismes responsables de la maturation du Vacherin proviennent de la flore naturelle du lait. Mais quelquefois, on ajoute au lait un starter de souches lactiques thermophiles à raison de 1 p. 1000 : ces cultures sont peu actives à la température de maturation du fromage, si bien que le but de cette adjonction est mal défini.

Cette étude a été faite parce que la maturation était très courte malgré la petite quantité de micro-organismes présents dans le lait.

\section{I. - Matériel et méthodes}

a) Stades de PRÉLÈvements

Des échantillons ont été prélevés dans trois fromageries situées à Arnex, La Sarraz et Agiez, dans le canton de Vaud, entre les lacs 


\section{TABLEAU 1}

Technologie du fromage de Vacherin et stades de prélèvement des échantillons

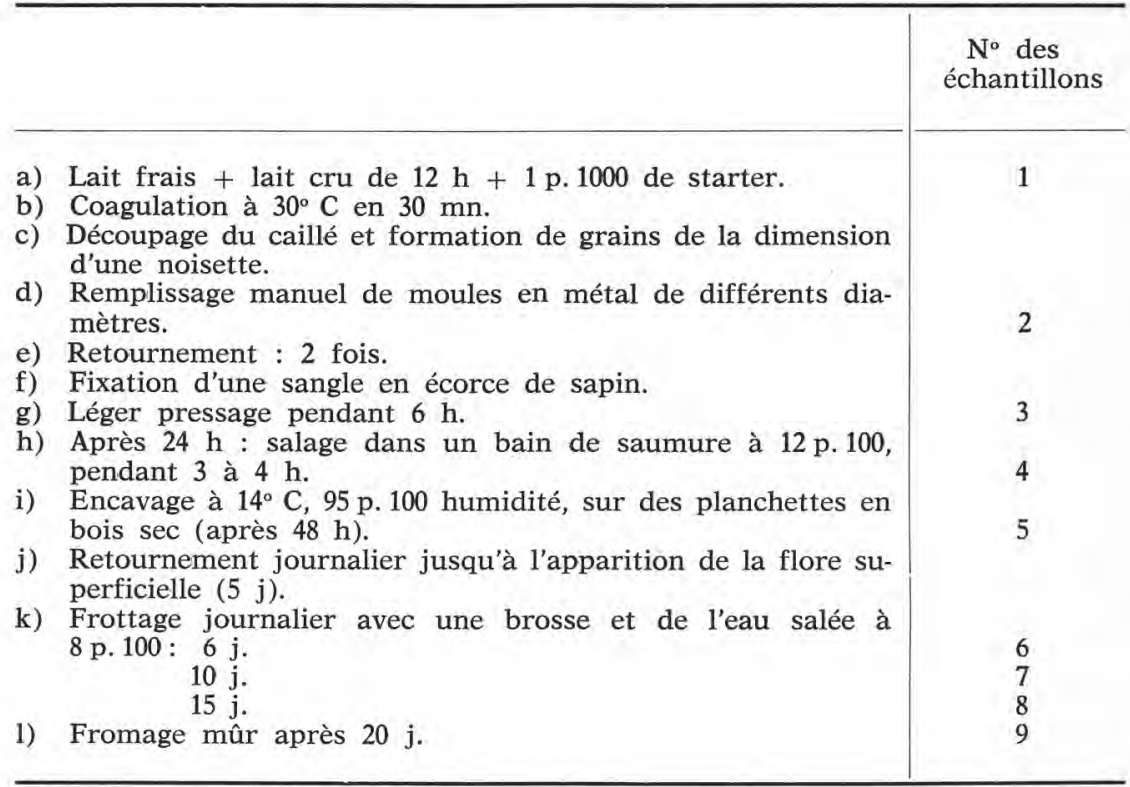

Léman et de Neuchâtel. Les prélèvements sont indiqués dans le tableau $\mathrm{n}^{\circ} 1$.

b) TeChNiques BactéRIOLOGIQUeS

- Lait : On en a prélevé des échantillons et on a fait des dilutions décimales dans une solution stérile de Ringer au quart (B.D.H.).

- Caillé et fromage : On a prélevé des échantillons de caillé et des échantillons dans le centre des fromages. Un gramme de ce matériel était mélangé dans un mortier, à l'aide d'un pilon, avec $10 \mathrm{ml}$ d'une solution de citrate de sodium à 1 p. 100 . On effectuait ensuite des dilutions décimales dans du Ringer stérile jusqu'à $10^{-16}$. On a modifié ces dilutions en fonction des résultats des dénombrements bactériens du lait.

- Dix milieux d'isolement ont été utilisés pour dénombrer les différents groupes de micro-organismes :

1) Germes totaux sur Plate Count Agar (Difco) [1] additionné de 0,02 p. 100 de pourpre de bromocrésol (Siegfried).

2) Streptocoques lactiques sur Plate Count Agar (Difco) additionné de 10 p. 100 de lait écrémé stérile.

3) Coliformes sur Desoxycholate Citrate Agar (Difco) [2].

4) Microcoques sur Mannitol Salt Agar (Difco) [3].

5) Levures et moisissures sur Potato Dextrose Agar (Difco) [4]. 
6) Lactobacilles sur M.R.S. (de Man, Rogosa et Sharpe) (Difco) [5].

7) Anaérobies sur Anaerobic Agar (Baltimore Biological Laboratories).

8) Streptocoques fécaux sur S.F. Streptococcus Agar (Difco) [6].

9) Bactéries propioniques sur P.T.L. Agar contenant par litre d'eau distillée :

$10 \mathrm{~g}$ de caséine Peptone (Merck).

$5 \mathrm{~g}$ de tryptone (Difco).

$20 \mathrm{~g}$ de Bacto Agar (Difco).

10) Bactéries butyriques sur Phytone Agar contenant par litre d'eau distillée :

20 g de phytone (Difco).

$2 \mathrm{~g}$ d'extrait de levures (Difco).

$0,2 \mathrm{~g}$ d'hydrochlorure de cystéine (Siegfried).

$2 \mathrm{~g}$ de chlorure de sodium (Merck).

$6 \mathrm{~g}$ de Bacto-Agar (Difco).

$\mathrm{pH}: 5,8$.

- Dénombrement des bactéries : On répartissait $1 \mathrm{ml}$ de chaque dilution dans une boîte de Pétri et on ajoutait $10 \mathrm{ml}$ de milieu de culture fondu et ramené à $50^{\circ} \mathrm{C}$. Après refroidissement et gélification, les plaques étaient incubées à $30^{\circ} \mathrm{C}$. Le dénombrement des bactéries butyriques était fait directement dans des tubes contenant $20 \mathrm{ml}$ de Phytone Agar. L'incubation des boîtes de Pétri contenant les milieux P.T.L., M.R.S. et Anaerobic Agar était faite sous azote.

Après $48 \mathrm{~h}$ d'incubation, on comptait les colonies à l'aide d'un compteur de colonies Gallenkamp. Sur Plate Count Agar additionné de lait, on n'a compté que les colonies produisant de l'acide, c'est-àdire les colonies jaunes.

- Techniques chimiques : Poids sec et humidité [7] : $1 \mathrm{~g}$ de fromage et $8 \mathrm{ml}$ d'eau bouillante ont été mélangés dans une capsule contenant $25 \mathrm{~g}$ de sable. Après évaporation $(30 \mathrm{mn}$ dans un bainmarie) le mélange a été séché pendant $6 \mathrm{~h}$ à $100^{\circ} \mathrm{C}$. Le poids sec a ensuite été déterminé.

$\mathrm{pH}$ et acidité (en degrés Soxhlet-Henkel) [8] : $10 \mathrm{~g}$ de fromage ont été émulsifiés dans un mortier avec de l'eau distillée froide, puis dilués à $100 \mathrm{ml}$. Le $\mathrm{pH}$ de la solution était mesuré et ensuite la solution a été titrée avec $\mathrm{NaOH} \mathrm{N} / 4$ jusqu'à un $\mathrm{pH}$ de 8,4 . Le nombre de degrés Soxhlet-Henkel est égal au nombre de $\mathrm{ml}$ de $\mathrm{NaOH}$ $\mathrm{N} / 4$ employés par $100 \mathrm{~g}$ de fromage.

Azote non-caséinique : $500 \mathrm{mg}$ de fromage ont été émulsifiés dans $70 \mathrm{ml}$ d'eau distillée à $40^{\circ} \mathrm{C}, 10 \mathrm{ml}$ d'acide acétique à $10 \mathrm{p} .100$ ont été mélangés avec l'émulsion, $1 \mathrm{ml}$ d'acétate de sodium ( $\mathrm{pH} \mathrm{4,6)}$ ajouté après $10 \mathrm{mn}$ et ensuite le mélange a été filtré. Le filtrat a été complété à $100 \mathrm{ml}$ avec l'eau distillée et la quantité d'azote dans $50 \mathrm{ml}$ de filtrat dosée d'après la méthode de Kjeldahl [9] .

Azote non-protéinique [10] : $500 \mathrm{mg}$ de fromage ont été émulsifiés dans $70 \mathrm{ml}$ d'eau, $10 \mathrm{ml}$ de cette émulsion ont été dilués à $50 \mathrm{ml}$ 
avec l'acide trichloracétique à $15 \mathrm{p} .100$, et filtrés après $10 \mathrm{mn}$. La quantité d'azote dans $30 \mathrm{ml}$ de filtrat a été dosée d'après la méthode de Kjeldahl.

\section{II. - Résultats}

1) RÉSultats bactériologiques

a) Le dénombrement des germes totaux a été fait sur Plate Count Agar.

Si on compare les résultats de la figure 1 avec le total des germes obtenus sur les milieux sélectifs, il est évident que tous les micro-organismes n'ont pas pu croître sur ces milieux. Malheureusement, on ne connaît aucun milieu qui permette la croissance de toutes les espèces présentes dans le fromage.

Cependant, les résultats nous indiquent clairement le développement des micro-organismes : le nombre de germes augmente très rapidement les 2 premiers jours, puis il reste stable.

b) La figure 2 montre le développement des streptocoques lactiques sur P.C.A. additionné de lait stérile. Il est intéressant de noter que le lait cru en contient un grand nombre.

Ces germes croissent rapidement pendant les 3 premiers jours et ils atteignent un maximum après $6 \mathrm{j}$.

c) La croissance des microcoques sur Mannitol Salt Agar est montrée sur la figure 3 . réduit.

Dans le caillé, le nombre des microcoques était considérablement

Il y avait une augmentation rapide pendant les 2 premiers jours, puis le nombre restait constant.

d) La figure 4 montre les résultats obtenus sur Desoxycholate Citrate Agar, milieu employé pour le dénombrement des coliformes.

Dans le lait, le niveau était très bas, et, malgré l'augmentation qui suivait, les résultats étaient très variables.

e) La figure 5 montre les résultats sur S.F. Streptococcus Agar. De nouveau, il y avait une augmentation rapide pendant les 2 premiers jours suivie d'une stabilisation pendant le reste de la maturation.

f) Le Potato Dextrose Agar a été employé pour dénombrer les levures et les moisissures. La figure 6 montre qu'il y en avait peu dans le lait et dans le caillé, et que leur nombre ne s'accroissait pas rapidement.

Des échantillons prélevés à la surface du fromage ont montré qu'il y avait 4 fois plus de levure que dans le centre. Ceci est peut- 


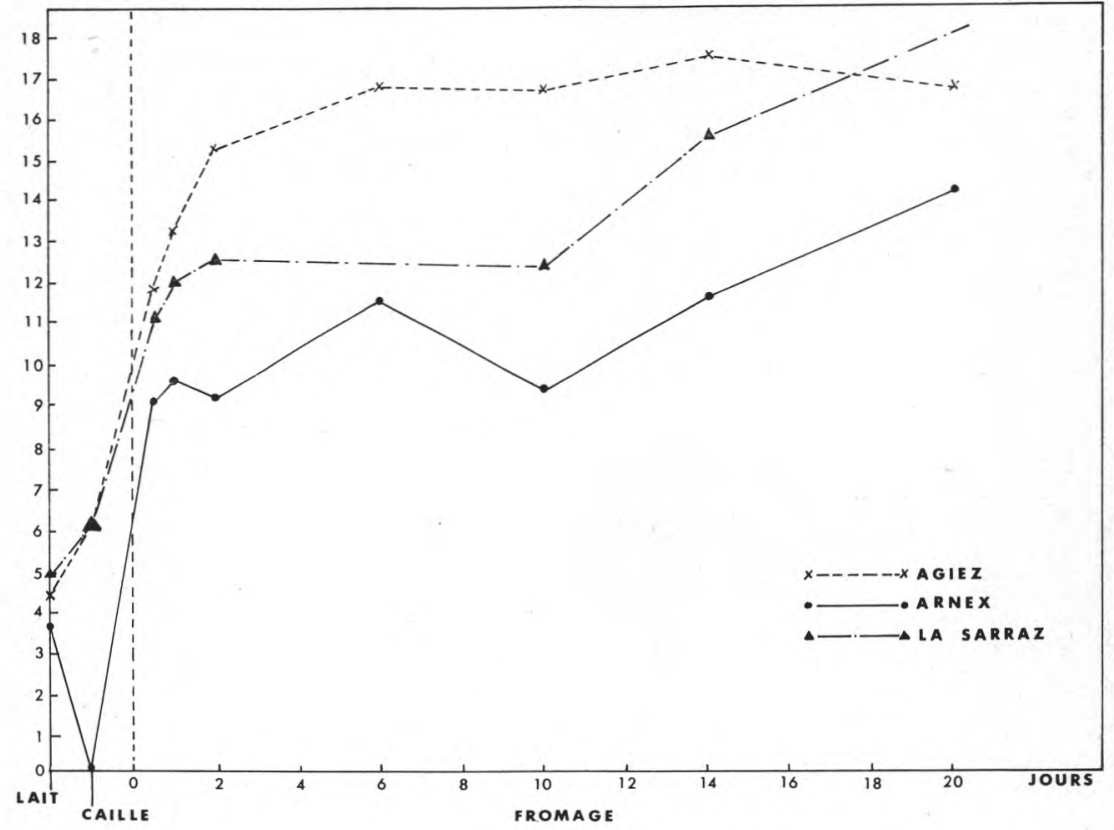

fig. 1

Nombre de germes totaux des trois séries d'échantillons de fromages, sur Plate Count Agar.

Coordonnées logarithmiques.

En ordonnées : nombre de micro-organismes par $\mathrm{g}$ de fromage.

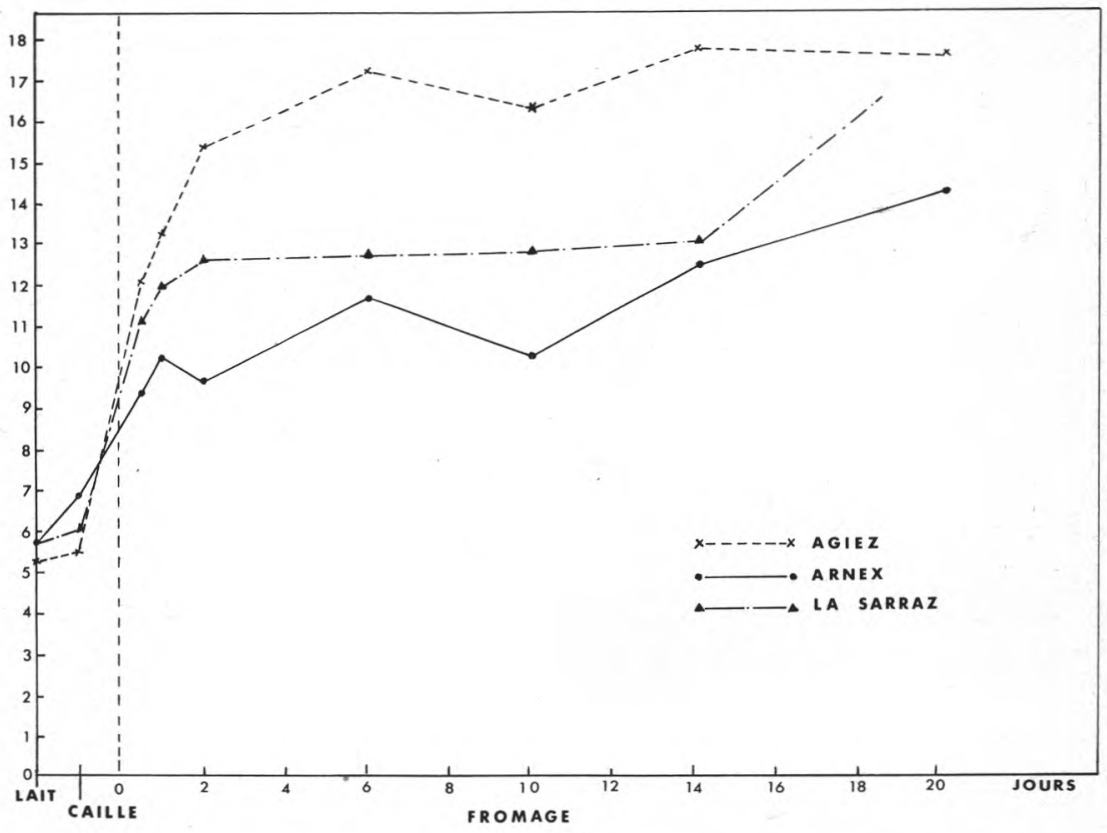

fig. 2

Nombre de germes acidifiants des trois séries d'échantillons sur Plate Count Agar, plus lait stérile.

Coordonnées logarithmiques.

En ordonnées : nombre de germes par $\mathrm{g}$ de fromage. 


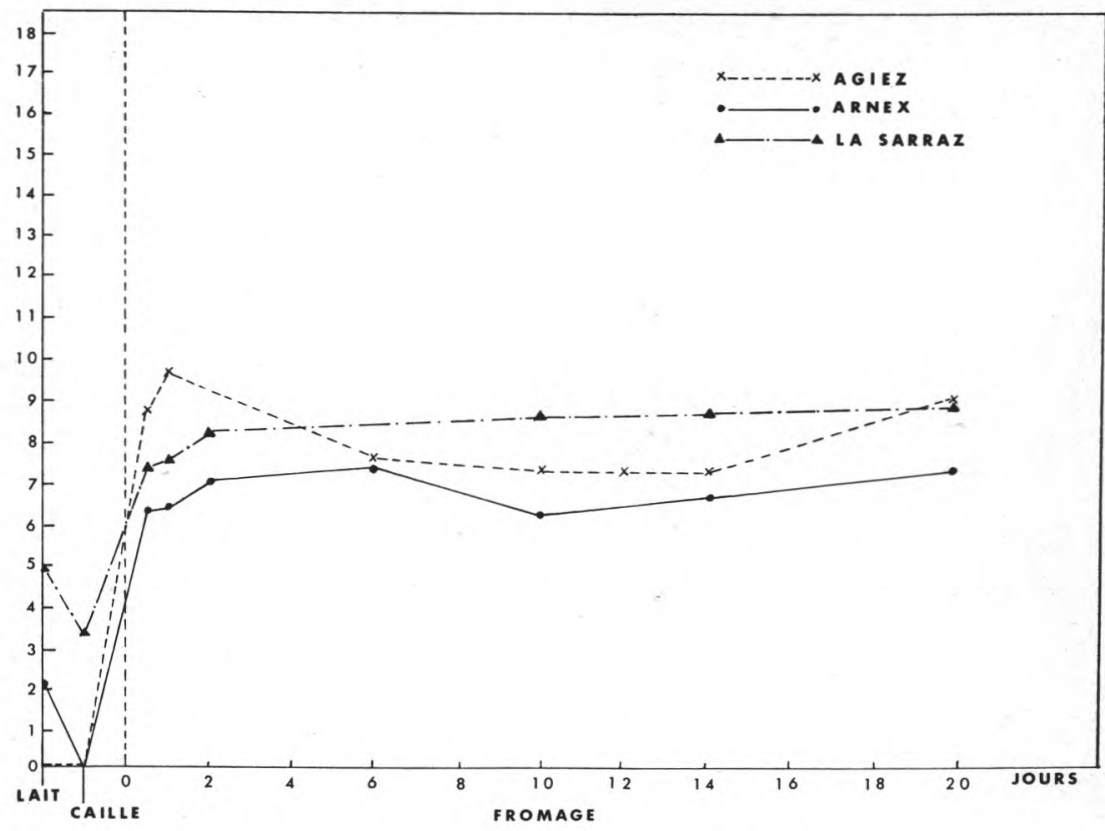

fig. 3

Nombre de staphylocoques et microcoques des trois séries d'échantillons sur Mannitol Salt Agar.

Coordonnées logarithmiques.

En ordonnées : nombre de germes par g de fromage.

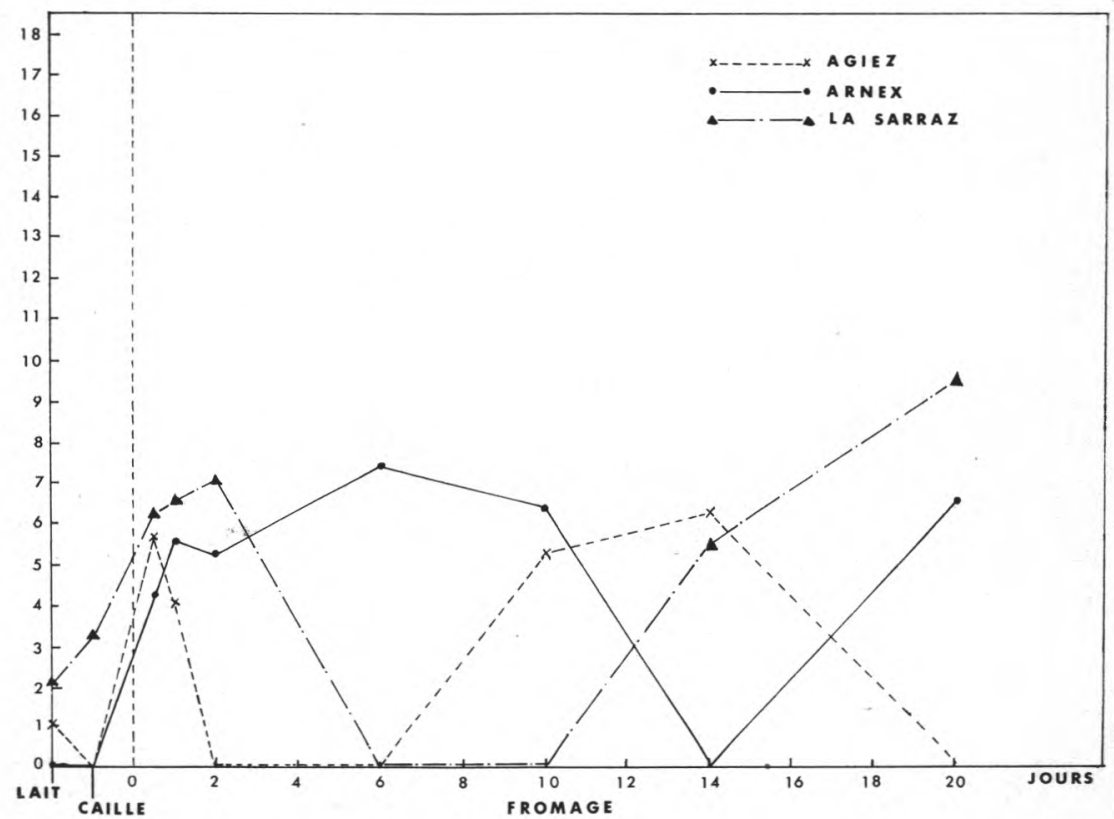

fig. 4

Nombre de bactéries coliformes des trois séries d'échantillons sur Desoxycholate Citrate Agar.

Coordonnées logarithmiques.

En ordonnées : nombre de germes par g de fromage. 


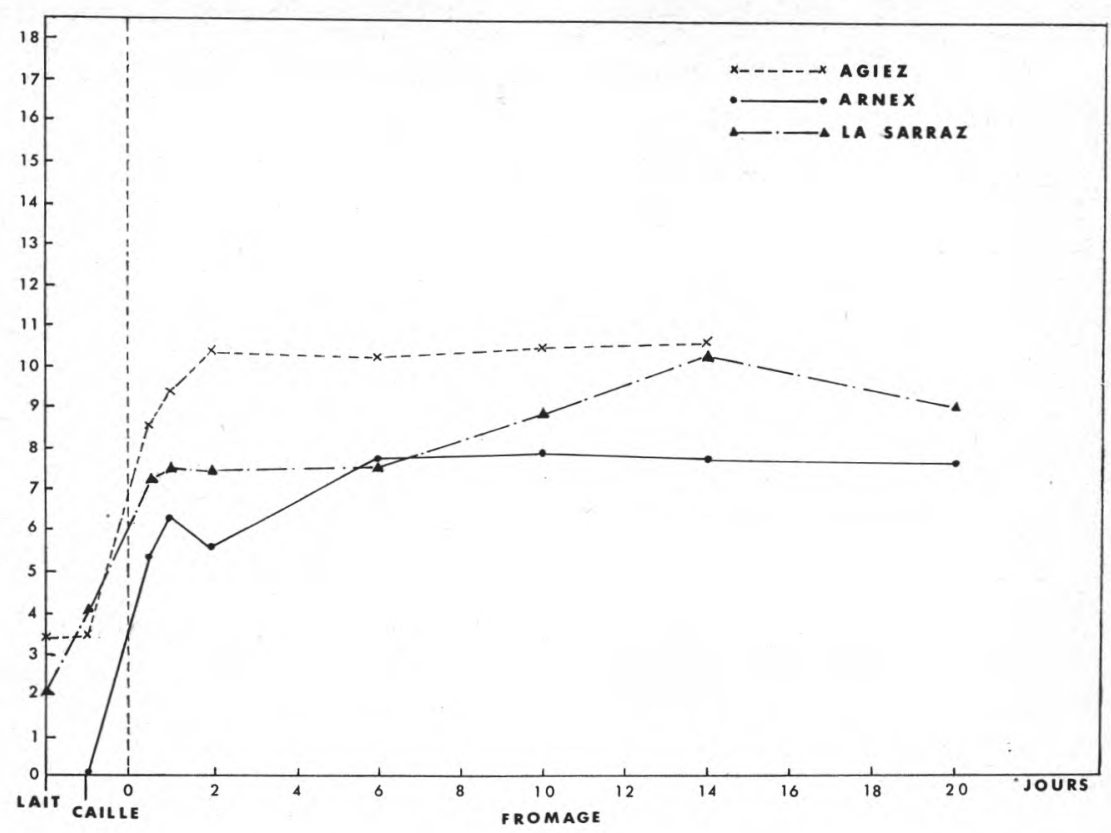

fig. 5

Nombre de streptocoques des trois séries d'échantillons sur S.F. Streptococcus Agar. Coordonnées logarithmiques.

En ordonnées : nombre de germes par $\mathrm{g}$ de fromage.

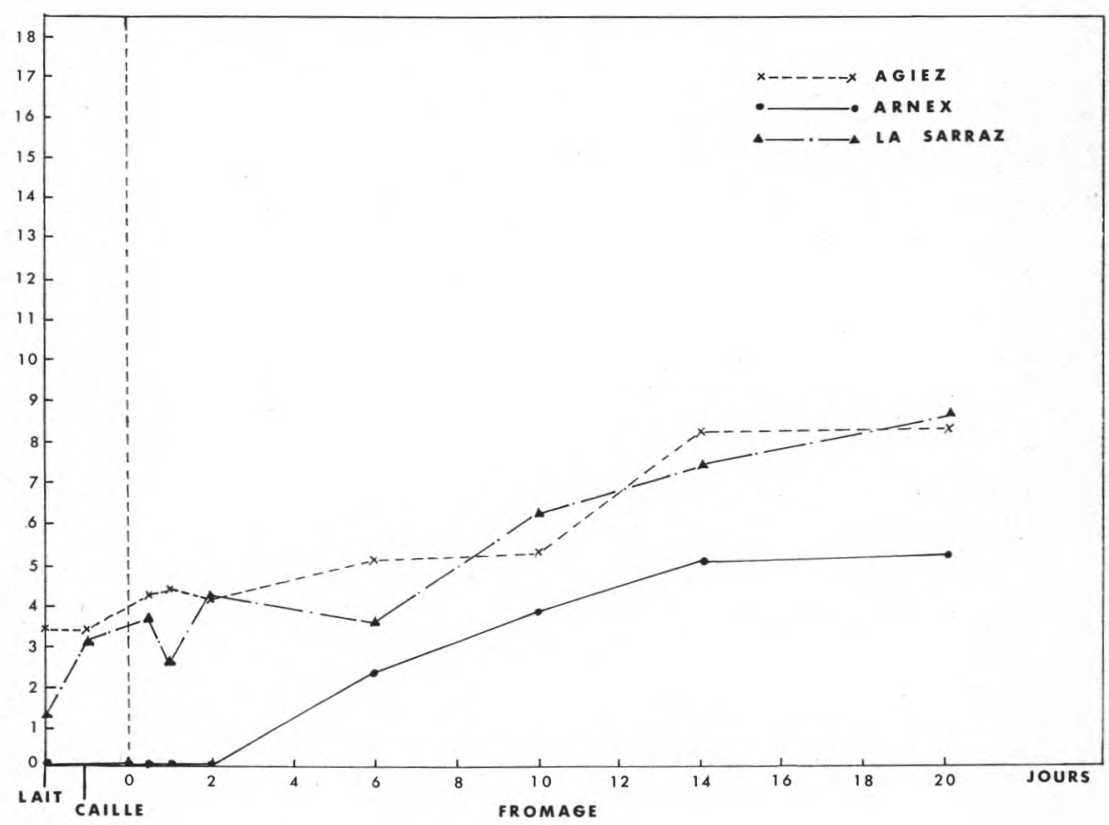

fig. 6

Nombre de levures et moisissures des trois séries d'échantillons sur Potato Dextrose Agar.

Coordonnées logarithmiques.

En ordonnées : nombre de germes par g de fromage. 
être dû à la contamination par l'air de la surface du fromage et au manque d'oxygène au centre.

g) La figure 7 montre les résultats obtenus sur le milieu M.R.S. utilisé pour dénombrer les Lactobacilles. Les micro-organismes se trouvaient en grand nombre dans le lait et se développaient rapidement dans le caillé. Après le premier salage, il y avait une légère diminution, suivie d'une deuxième augmentation rapide jusqu'au $8^{\text {me }} \mathrm{j}$.

h) La figure 8 montre les résultats sur P.T.L. Agar employé pour dénombrer les bactéries propioniques. Il existait une légère différence entre les échantillons pris dans les différentes caves, mais la croissance effective était la même.

Encore une fois, il y avait un développement rapide pendant les 2 premiers jours, suivi d'une augmentation moins rapide pendant le reste de la maturation.

i) Les résultats sur Phytone Agar utilisé pour dénombrer les bactéries butyriques sont montrés sur la figure 9. Ces germes étaient en nombre très limité. Les échantillons d'Arnex en contenaient très peu pendant les 6 premiers jours de la maturation. Par contre, les échantillons des deux autres caves ont atteint leur niveau maximum après $2 \mathrm{j}$.

j) La dernière figure (fig. 10), concerne le développement de bactéries anaérobies.

Les échantillons d'Arnez et de La Sarraz ont montré très peu d'anaérobies avant le $6^{\text {me }} \mathrm{j}$, contrairement aux échantillons d'Agiez où le nombre de ces bactéries a atteint son maximum après le $2^{\text {me }}$ jour, puis a décliné.

\section{2) Résultats chimiques}

Les résultats sont schématisés sur les figures 11 à 15. La figure 11 montre le contenu en eau des fromages ; après une chute très rapide au départ, le niveau est resté constant.

Dans la croûte, la teneur en eau est tombée encore plus, certainement sous l'effet de l'évaporation.

Les courbes de $\mathrm{pH}$ et d'acidité sont présentées respectivement sur les figures 12 et 13 .

Les deux courbes correspondent très bien; quand le $\mathrm{pH}$ descend, l'acidité monte. Il est intéressant de noter qu'après l'augmentation initiale, l'acidité du centre du fromage reste constante pendant les 4 premiers jours. L'acidité de la croûte tombe très rapidement après $10 \mathrm{j}$, puis demeure constante pendant le reste de la maturation. Ceci peut être dû à la présence, dans la croûte, d'un plus grand nombre de micro-organismes utilisant l'acide lactique, tels que les levures. 


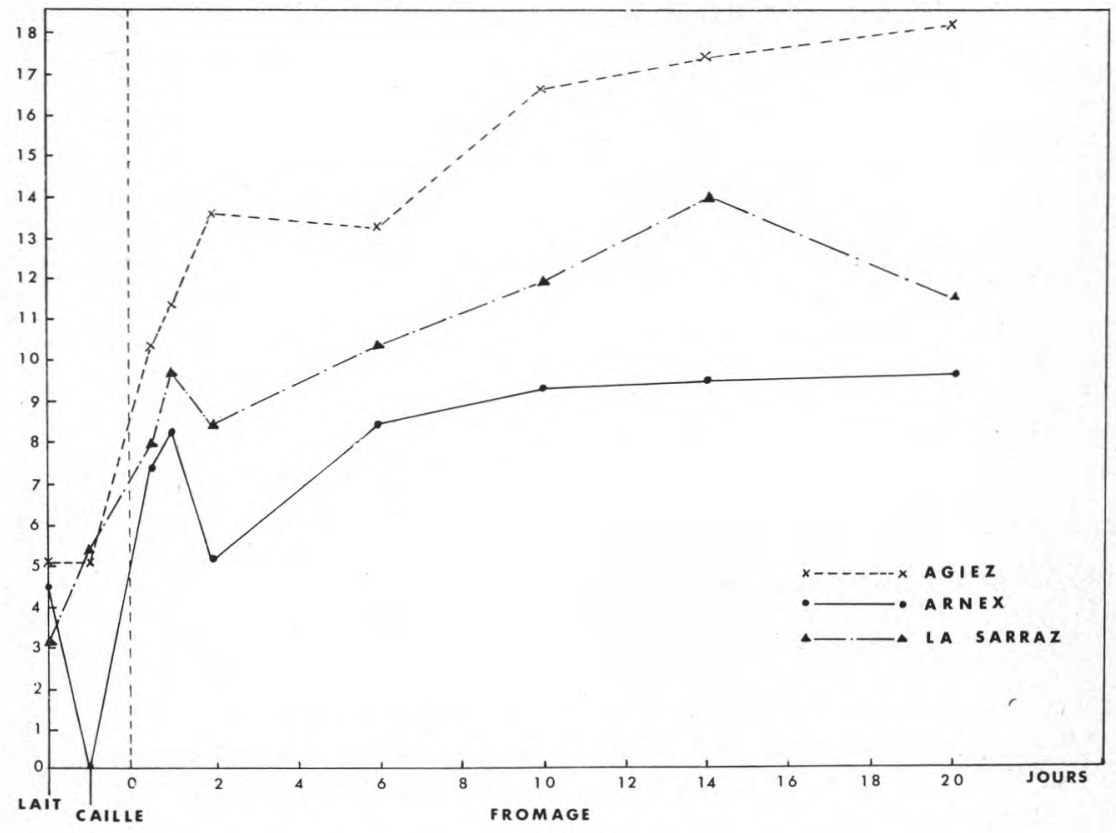

fig. 7

Nombre de Lactobacilles des trois séries d'échantillons sur de Mann, Rogosa et Sharpe Agar.

Coordonnées logarithmiques.

En ordonnées : nombre de germes par $\mathrm{g}$ de fromage.

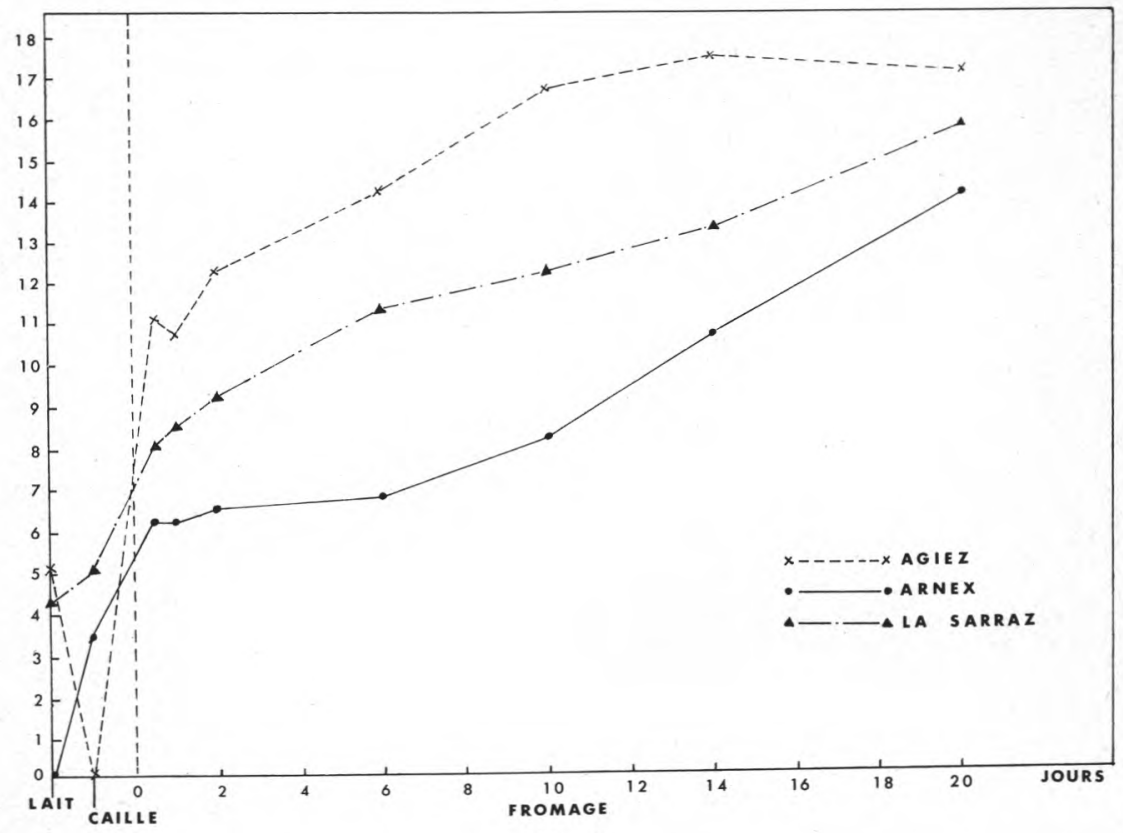

fig. 8

Nombre de Bactéries propioniques des trois séries d'échantillons sur P.T.L. Agar. Coordonnées logarithmiques.

En ordonnées : nombre de germes par $\mathrm{g}$ de fromage. 


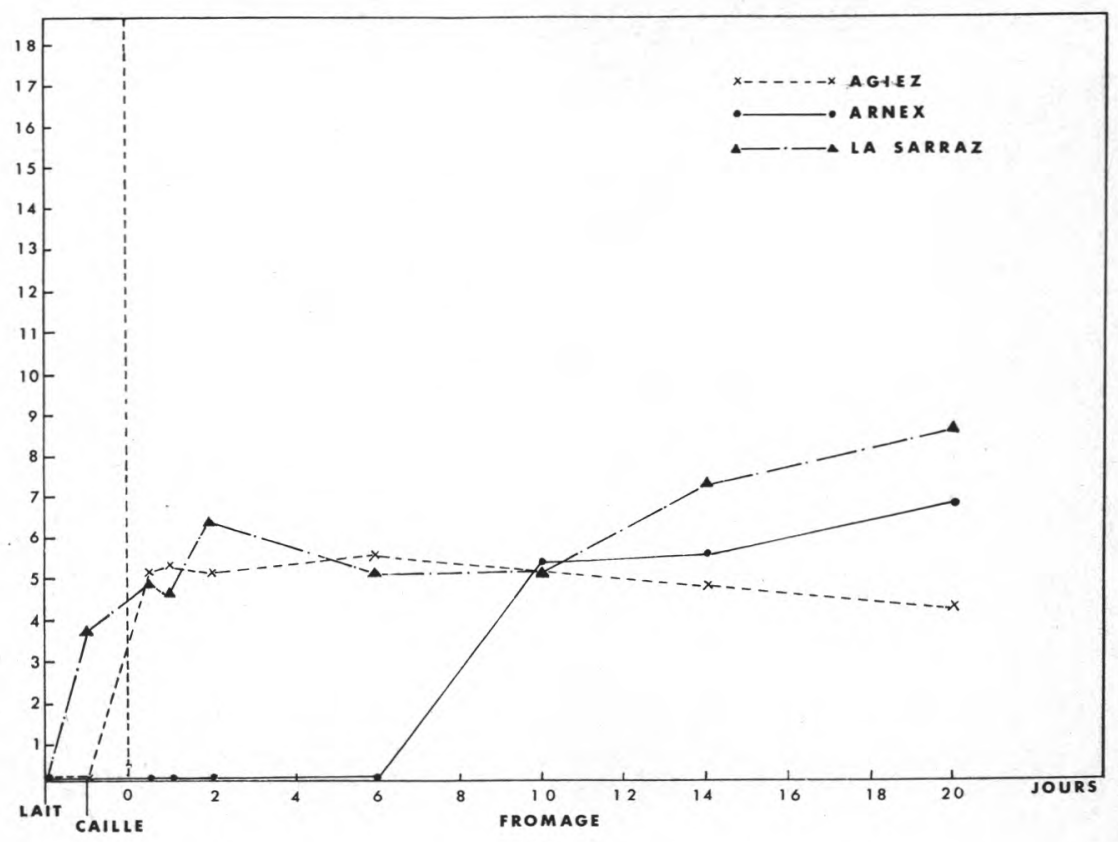

fig. 9

Nombre de Bactéries butyriques des trois séries d'échantillons sur Phytone Agar. Coordonnées logarithmiques.

En ordonnées : nombre de germes par $\mathrm{g}$ de fromage.

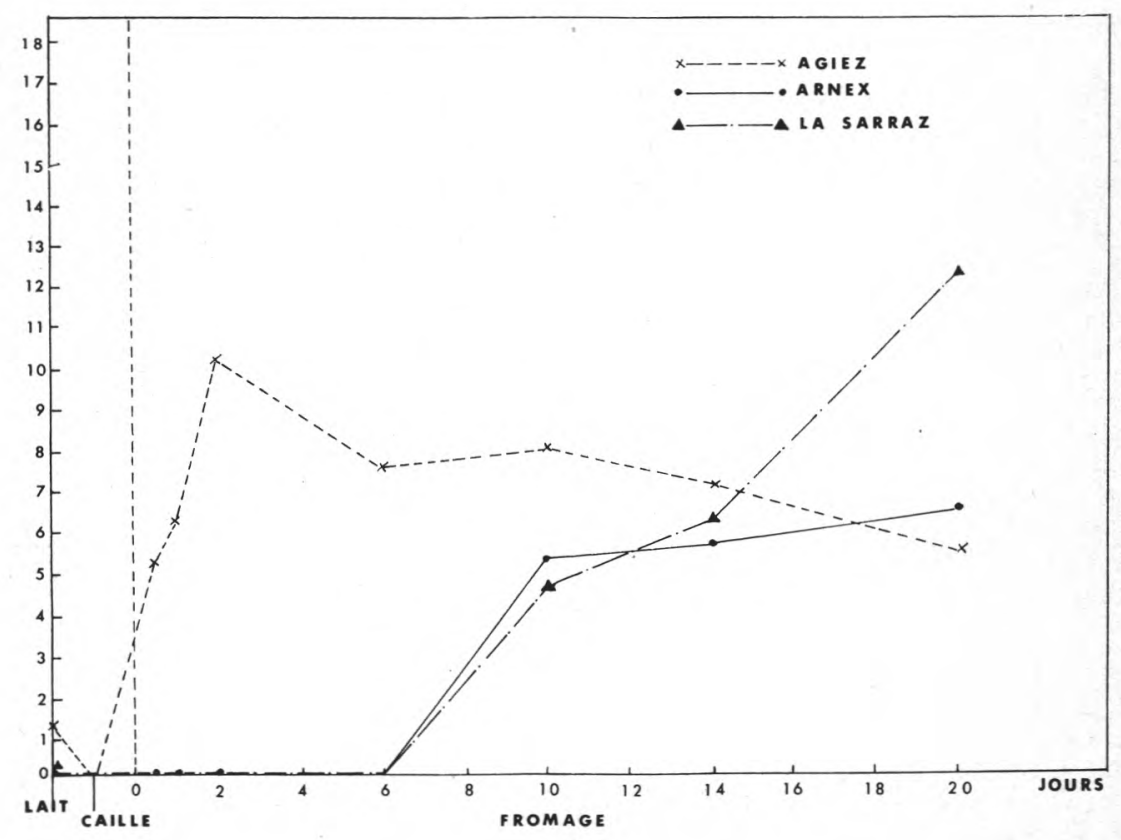

fig. 10

Nombre de Bactéries anaérobies des trois séries d'échantillons sur Anaerobic Agar. Coordonnées logarithmiques.

En ordonnées : nombre de germes par $\mathrm{g}$ de fromage. 


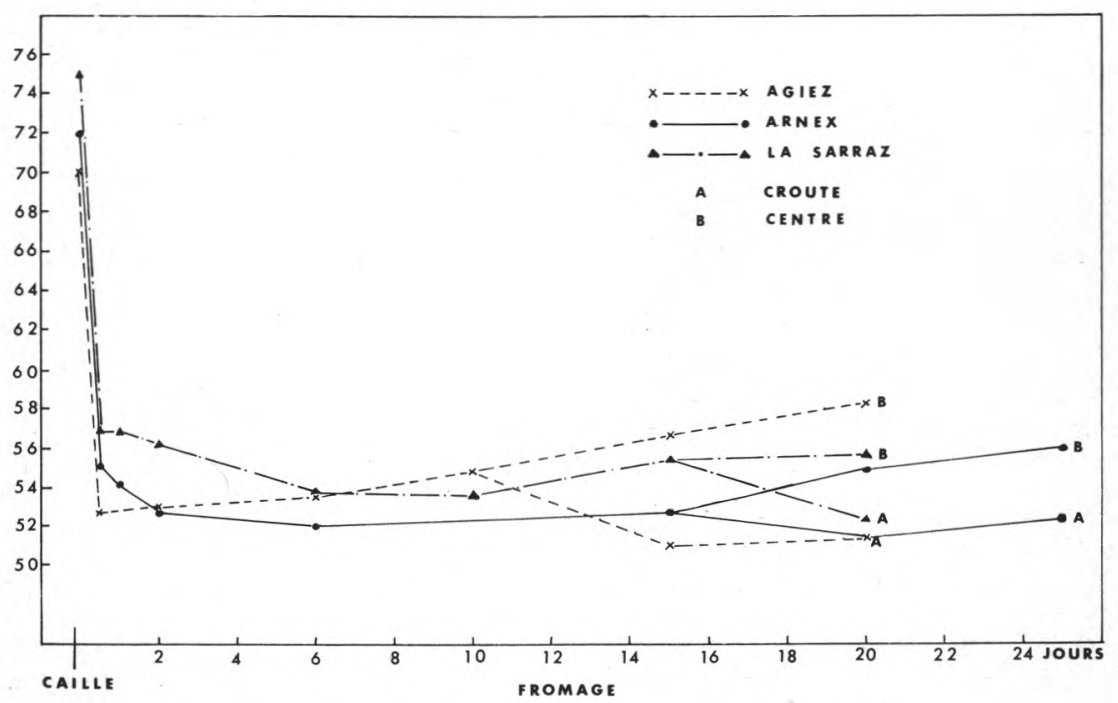

fig. 11

Modifications dans la teneur en eau des trois séries d'échantillons.

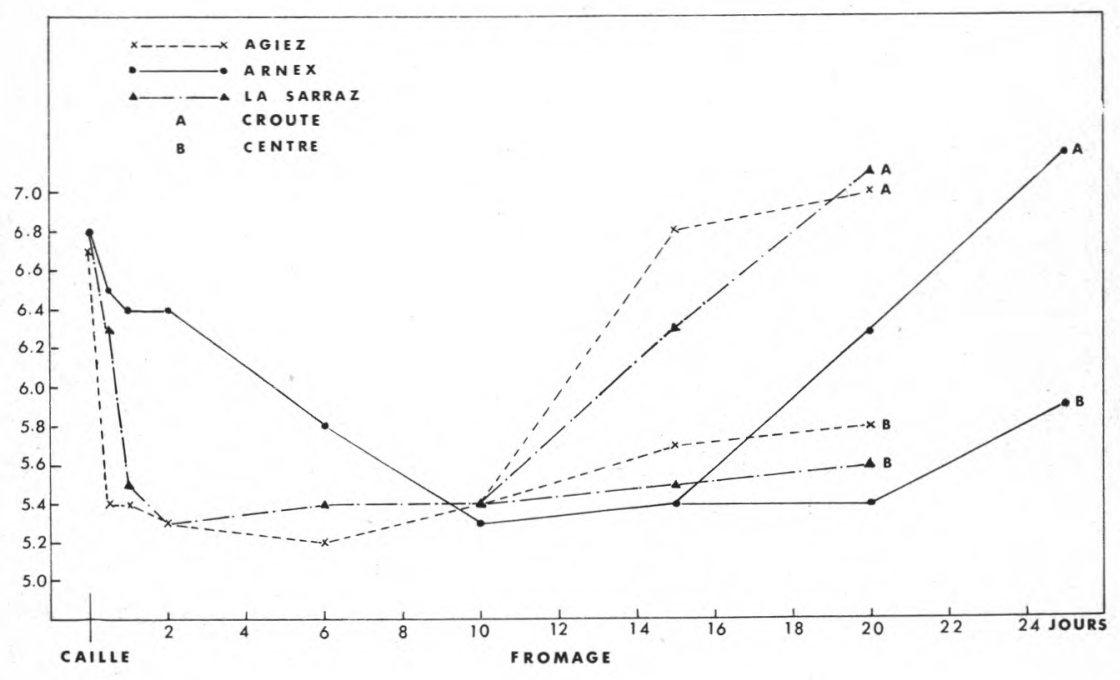

fig. 12

Modifications du $\mathrm{pH}$ des trois séries d'échantillons. 


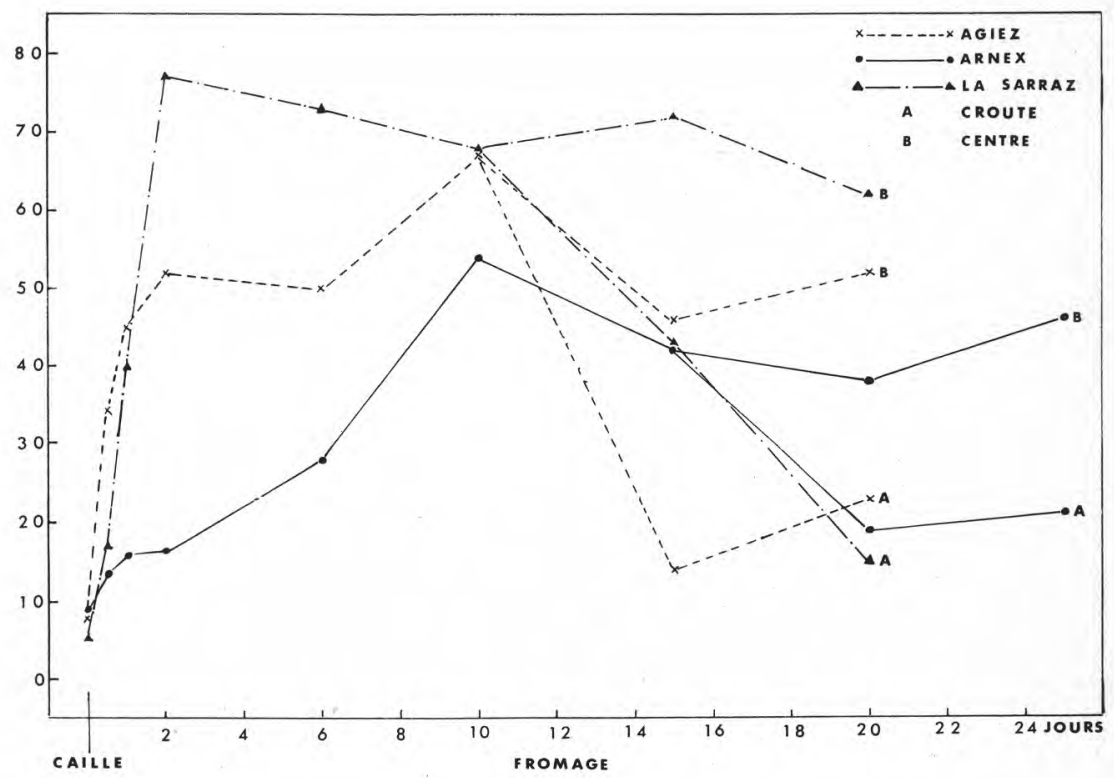

fig 13

Modifications de l'acidité des trois séries d'échantillons.

Acidité exprimée en degrés Soxhlet-Henkel.

Les résultats de l'azote non caséinique sont indiqués dans la figure 14.

Son taux baisse très rapidement pendant la formation du caillé car il est entraîné avec le petit lait.

Le niveau reste ensuite constant pendant les 6 premiers jours, puis il augmente jusqu'à la fin de la maturation.

Encore une fois, il y a une différence entre la croûte et le centre du fromage : la quantité d'azote non caséinique s'accroît davantage dans la croûte.

Enfin, la figure 15 montre les résultats de l'azote non protéinique, qui sont semblables à ceux de la figure 14 .

La différence entre la croûte et le centre du fromage n'est pas aussi grande.

Notons cependant que l'augmentation de l'azote non protéinique commence avant celle de l'azote non caséinique. 


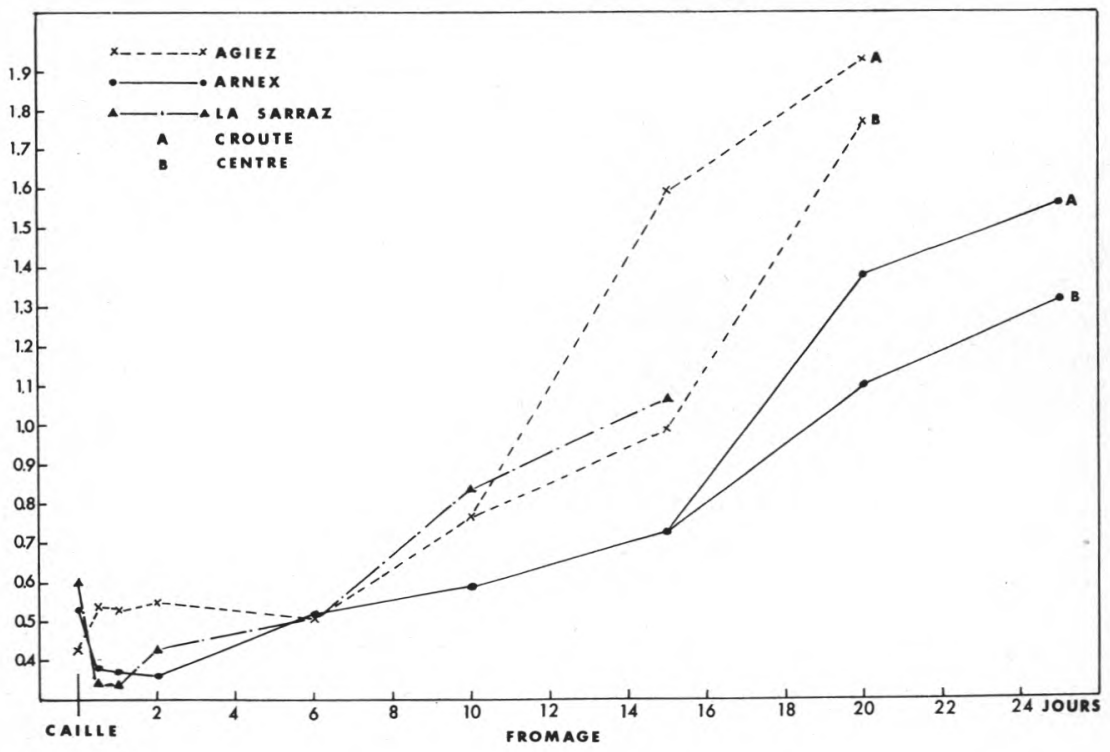

fig 14

Modifications de la quantité d'azote non caséinique des trois séries d'échantillons. Résultats exprimés en p. 100 de la matière sèche.

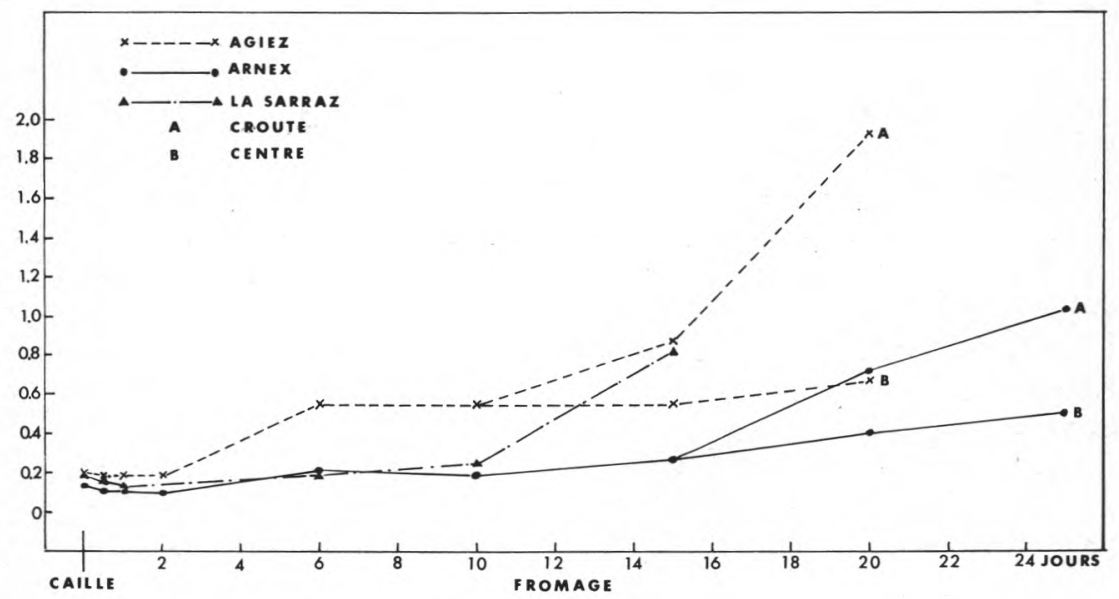

fig. 15

Modifications de la quantité d'azote non protéinique des trois séries d'échantillons. Résultats exprimés en p. 100 de la matière sèche. 


\section{III. - Discussion}

Avant de discuter les corrélations entre les résultats microbiologiques et chimiques, il est nécessaire de clarifier quelques points.

Cette méthode d'étude de la microflore d'un fromage permet seulement de tirer des conclusions générales. Cela provient des erreurs d'échantillonnages et d'autres causes que nous allons examiner. Tout d'abord, les échantillons prélevés aux divers stades de la maturation proviennent, non pas du même fromage, mais de différents fromages faits avec la même cuve.

Les erreurs les plus significatives proviennent des dilutions et des comptages des plaques. Les résultats des dénombrements de germes s'élèvent à $10^{18}$ cellules par gramme. Si on calcule la quantité de fromage correspondant à un tel nombre de germes, il est évident qu'il aurait fallu prélever beaucoup plus de $1 \mathrm{~g}$, quantité prise pour chaque échantillon, pour arriver à un tel chiffre.

Un bon exemple d'erreur due à l'échantillonnage nous est fourni par l'observation des résultats de la figure 4, relatifs aux coliformes: ces germes ne proviennent pas du lait qui en est exempt, mais des manipulations successives dont les fromages font l'objet. Les niveaux variables de contamination ne sont pas le reflet d'une variation dans le nombre des coliformes au cours de la maturation mais d'une contamination variable selon les fromages. Notons cependant que le taux de coliformes est tout à fait normal pour un fromage [11].

Malgré toutes ces inexactitudes, les résultats chimiques et bactériologiques obtenus nous permettent de tirer certaines conclusions.

Les résultats des échantillons prélevés à Arnex, seule fromagerie où le lait est partiellement pasteurisé et inoculé avec un starter, montrent que les plus basses quantités d'azote soluble sont en relation avec les plus petits nombres de germes.

Le $\mathrm{pH}$ baisse beaucoup plus lentement que pour les échantillons des autres caves parce que les bactéries produisant de l'acide se développent plus lentement. L'hydrolyse de la caséine et des autres protéines est aussi beaucoup plus lente.

Les résultats des échantillons d'Agiez et de La Sarraz sont plus typiques : la quantité de caséine diminue graduellement au cours de la maturation, ce qui correspond à une augmentation de la quantité de bactéries protéolytiques [12].

Les acides aminés apparaissent aux derniers stades du développement. Il est intéressant de noter que la protéolyse augmente en même temps que le $\mathrm{pH}$.

Le $\mathrm{pH}$ monte plus rapidement dans la croûte que dans le centre du fromage ; il en est de même pour l'azote non protéinique et non caséinique. Ces résultats ont été confirmés par l'analyse bactériologique de la croûte et du centre : il y a davantage de bactéries et 
de levures dans la croûte et la dégradation de la caséine y est plus intense.

En comparant les changements chimiques et microbiens des fromages avec leur goût et leur consistance, on arrive à établir des corrélations intéressantes : le fromage produit à La Sarraz avait davantage de goût que les autres ; et parallèlement, la flore totale et la protéolyse de ce fromage étaient plus importantes, comme le démontre la plus grande liquéfaction du centre du fromage, surtout au terme de la maturation. C'est à ce moment et dans ces échantillons que le nombre des bactéries anaérobies, en particulier les bactéries propioniques et butyriques, était le plus élevé.

Il en résulte que la maturation et donc la qualité du Vacherin sont influencées par divers facteurs. Le premier semble être le développement des germes totaux qui atteignent leur maximum au bout de $3 \mathrm{j}$.

La croissance rapide et précoce des bactéries lactiques et protéolytiques semble aussi importante. Ce développement de germes aérobies doit être suivi par celui des anaérobies, mais cependant pas trop tôt.

Les interactions entre les différentes espèces de bactéries entrâ̂nent des changements chimiques dans le fromage, en dégradant les protéines, et aussi, en produisant des substances extracellulaires comme les acides butyriques et propioniques qui donnent le goût et la texture caractéristiques au fromage.

Il ressort de cette étude qu'avec les techniques traditionnelles employées en fromagerie, on obtient des fromages d'une qualité très standardisée malgré le manque de contrôle microbiologique.

\section{Remerciements}

Nous remercions $M$. R. Pousaz pour son excellente assistance technique au cours de ce travail, ainsi que M. K. R. Traelnes, Mlles M. Carels, $R$. Astruc et Mme S. K. Wood pour leur aide dans la préparation de cette publication.

\section{Rés u m é}

On a étudié la chimie et la microbiologie du fromage de Vacherin sur des échantillons prélevés dans trois fromageries situées en Suisse, dans le Canton de Vaud, à Arnex, Agiez et La Sarraz.

En examinant les fromages provenant d'une même fromagerie, on a pu observer des modifications caractéristiques dans la composition chimique et la flore microbienne du fromage au cours de la maturation.

Pendant les 3 premiers jours, il y a une augmentation du nombre total de micro-organismes suivie d'une stabilisation. 
Les proportions entre les différents germes changent. Les bactéries anaérobies, très lentes à se développer, sont celles qui contribuent à donner au fromage son goût caractéristique. Pendant les quelques premiers jours, il y a une dégradation rapide de la caséine ; c'est à la fin de la maturation qu'apparaissent les acides aminés. Les produits de dégradation de la caséine sont en plus grande quantité dans la croûte que dans le centre du fromage. La raison en est que la population microbienne est plus abondante dans la croûte que dans le fromage même.

Finalement, on a observé que la quantité de micro-organismes et par suite de produits de dégradation de la caséine avaient de l'influence sur le goût et la texture du fromage.

Les fromages de La Sarraz étaient plus crémeux et avaient un goût plus typique que les autres. Parallèlement, ils contenaient le plus grand nombre de germes, notamment des germes anaérobies, et la plus grande quantité de produits de dégradation de la caséine.

\section{Su $\mathrm{m} m$ a $\mathrm{ry}$}

A chemical and microbial study of vacherin cheese was carried out on samples from three cheese making factories. These were situated at Arnex, Agiez and La Sarraz in the canton of Vaud in Switzerland.

By examining cheese from the same factory, it was possible to observe certain characteristic changes in the chemical and microbial content of the cheese during ripening. There was an increase in the total number of microorganisms during the first three days after which time the numbers remained constant.

Although the total number of microorganisms remained constant, the proportions of the different types of bacteria changed. The anaerobic bacteria were very slow to develop; and it is these bacteria which help give the cheese its characteristic flavour. There was a rapid breakdown of casein during the first few days followed by the appearance of amino acids at the end of the ripening. When the crust was compared with the centre of the cheese it was found to contain a higher quantity of breakdown products of casein. The reason for this was seen when a microbial count was carried out on the crust showing much larger numbers of bacteria than in the centre.

Finally, the influence of the quantity of microorganisms and subsequent breakdown of casein on the flavour and texture of the cheese is discussed.

It was found that the cheese from La Sarraz was more creamy and had a more typical flavour than the other. This also had the highest number of bacteria, especially anaerobic bacteria, and the highest quantity of breakdown products of casein. 


\section{Bibliographie}

[1] Standard methods for the examination of dairy products. Microbial and chemical. Am. Public Health Ass. Inc. (1960).

[2] Diagnostic procedures and reagents. 3rd edition (1950), p. 212.

[3] Chapman (G. H.) (1945). - The significance of sodium chloride in studies of staphylococci. J. Bact., 50, p. 201.

[4] Standard methods for the examination of dairy products. 9th edition (1948), p. 157.

[5] De Man (J. C.), Rogosa (M.) and Sharpe (M. E.) (1960). - A medium for the cultivation of lactobacilli. J. Appl. Bact., 23, p. 130.

[6] Hajne and PerRy (1943). - Comparative study of presunmptive and comfirmating media for bacteria of the coliform group and for fecal streptococci. Am. J. Publ. Health, 33, p. 550.

[7] Politi (I.) (1960). - Chimica del latte e dei latteoni. Centro Sperimentale Latte, Milano.

[8] Official methods of analysis of the Association of Official Agricultural Chemistry. 9th edition (1960).

[9] Bradstreet (R. B.) (1965). - The Kjeldahl method for organic nitrogen. Academic Press, New-York (1965).

[10] Lenoir (J.) (1963). - Note sur la dégradation des protides au cours de la maturation du Camembert. Le Lait, 43, p. 154.

[11] Galzin (M.), Galzy (P.) et Bret (G.) (1970). - Etude de la flore de levure dans le fromage de Roquefort. Le Lait, 491, p. 1.

[12] OhmiYa (K.) and Sato (Y.) (1969). - Studies on the proteolytic action of dairy lactic acid bacteria. Agr. Biol. Chem., 33, n 5, p. 669. 